misconceptions at an institutional level about how science works misconceptions that stifle risk-taking and promote narrow conformity. But some suspect that such cosmetic efforts do little to address the problems created by a strongly hierarchical research culture, where an immense pressure to succeed might be seen as a precondition for the sorts of abuses evident in the case of disgraced cloning researcher Woo Suk Hwang in South Korea.

An even deeper question is whether a truly vibrant scientific culture is possible without a more widespread societal commitment to free expression. The right to challenge authority, and to doubt everything, is central to scientific enquiry. And no country can be a major scientific player in the modern world unless its scientists can collaborate with researchers from elsewhere. A poor record on human rights will not make this impossible - but it will make it more difficult. Scientists do, largely, have a commitment to human rights, and will be happier working with colleagues who share that commitment.

Perhaps it is good news that China's current success story continues to be characterized by a canny pragmatism. Granted, this attitude can sometimes make it seem as though everything is motivated by the economic bottom line. For example, although it would be too cynical to suggest that global warming and environmental degradation are now being taken seriously only because they eat into China's gross domestic product, that is surely one big reason for the concern. Yet, motivated by that same pragmatism, the Chinese authorities are increasingly recognizing that getting the best value from its scientists means providing them with adequate funds and minimal interference, even if this sees them straying 'off-message'. Many outside scientists have been surprised to find that Chinese graduate students and postdocs are now quite willing to challenge their professors. Exaggerated deference to authority is clearly on the wane in China's younger generation of scientists - and who knows how far that pragmatic liberalization will go?

In the meantime, the rest of the world can surely benefit from the self-confidence that will make China a source not just of skilled, hardworking postdocs, but of a new agenda, informed by a tradition of innovation of almost unparalleled antiquity and sophistication.

\section{Mind the gaps}

\section{The incoming US administration can and should reverse the neglect of Earth observations.}

A t many places around the world, it is possible to feel the climate changing: the ice cracking, the soil waking earlier in the spring. Perhaps such feelings are merely rooted in a heightened awareness of global warming. Whatever the case, the true significance of such localized experiences can be assessed only through extensive data on key Earth processes over time.

Given the effects of those processes, it would be smart and responsible for policy-makers and scientists to focus on strengthening the international strategy for collecting key Earth observations for the foreseeable future. After all, data on such variables as soil moisture, wind speed and direction at various altitudes, and atmospheric temperature and pressure are essential for improving climate models in the future, and for informing mitigation efforts. Moreover, many of the programmatic elements for global data-gathering are already in place - one notable example being the consortium pursuing the Global Earth Observation System of Systems (GEOSS), which comprises 74 nations plus the European Commission.

And yet the United States, potentially one of the central participants in any such international system, has allowed short-term budgetary considerations to direct too many of its decisions. In June 2006, for example, cost over-runs caught up with the National Polar-orbiting Operational Environmental Satellite System, a proposed joint military and civil satellite programme intended to replace all US weather satellites. Several long-term climate data sensors were axed or pared down, including those measuring the variables mentioned above. A few months later, the Geostationary Operational Environmental Satellites programme got the same treatment.

Earlier this month, the National Academies' National Research Council (NRC) released a report that suggests ways to save from oblivion the data those sensors would have collected. The council identifies important sensors to be restored to the missions from which they were cut, and recommends that others should be put on new satellites or should hitch rides on other scheduled missions.

After presenting this patchwork solution, the report stresses the importance of a long-term strategy for climate observation. This section should be required reading for anyone hoping for a political appointment at NASA, the National Oceanic and Atmospheric Administration (NOAA) or the US Geological Survey in 2009. In fact, the hopefuls should add the NRC's decadal survey Earth Science and Applications from Space to their reading list. What is clear from both documents is that the United States does not have a unified strategy for collecting these observations, and that the three agencies involved have not been able to avoid gaps in data or unnecessary duplication of data gathered by other nations.

The White House will need to exert pressure to make such a strategy a high priority. Neither of the two presidential candidates, John McCain and Barack Obama, has said much, if anything, about Earth observations. Providing for continuous high-quality climate data would be a substantial legacy, serving the interests of both US citizens and the rest of the world for decades to come.

The NRC's suggestions should be taken up immediately, and the next US president should move quickly to appoint directors to NOAA and NASA who see Earth monitoring as a priority. Commendably, the current head of NOAA, Conrad Lautenbacher, has been a driving force behind GEOSS. The occasionally sceptical remarks about climate change from NASA administrator Michael Griffin make him less of an example to follow.

At the very least, the new agency heads should commit to the monitoring of the essential climate variables outlined by the Global Climate Observing System. They should work with other countries through GEOSS to make sure that data are not needlessly duplicated. Satellites can provoke secrecy and competition between nations that, instead, must pull together to monitor the well-being of the planet on which they all depend. 